\title{
Some architectural aspects of tree ageing
}

\author{
D. Barthelemy, C. Edelin and F. Hallé
}

Laboratoire de Botanique, Institut Botanique (UA327 du CNRS), 163, rue A. Broussonet, 34000 Montpellier, France

\section{Introduction}

Despite the numerous investigations on tree ageing, among which the work of Schaffalitzky de Muckadell (1959) is certainly the most famous, we are still far from being able to give a definition of this general process. This, we believe, mainly results from the difficulty to identify precise markers of development and of the physiological state of an old tree. Using the concepts of architectural model and reiteration (Halle et al., 1978), architectural studies, along with other sectors of research, may contribute to increasing our knowledge of tree ageing, by analyzing and describing the successive morphogenetic processes that occur between crown construction and the death of woody plants. We have only a few data on this problem, but recent observations lead us to distinguish 3 major kinds of architectural events during this period.

\section{The reversion to a juvenile-like archi- tecture}

Between germination and crown construction, the tree shows a series of architectures that arise according to an invariable sequence of genetically determined events. For instance, in Virola surinamensis (Roland.) Warb. (Myristicaceae), a South American tropical tree which conforms to Massart's model, the first phase of growth consists of the development of tiers of plagiotropic branches on the orthotropic trunk, a very simple architecture which corresponds to the architectural unit (Edelin, 1977) of this species. The second phase, which starts when the organism is $5-7 \mathrm{~m}$ high, is marked by the development of forks at the extremity of the branches; each axis of this fork is a partial reiterated complex. The third phase begins when the tree is $15-20 \mathrm{~m}$ tall: total reiterated complexes grow out vertically at the tip of the branches. These reiterated complexes are perennial and, together with the branches from which they are issued, they build up the framework of the crown. Further, we observe that the new branches growing out of the trunk no longer support total reiterated complexes, but they still produce terminal forks. Higher on the trunk, before it stops growing definitively, the last branches developed do not bear any kind of reiterated complex (Fig. 1).

Thus, reiteration seems to characterize a momentary and relatively short phase of tree development, after which, the or- 


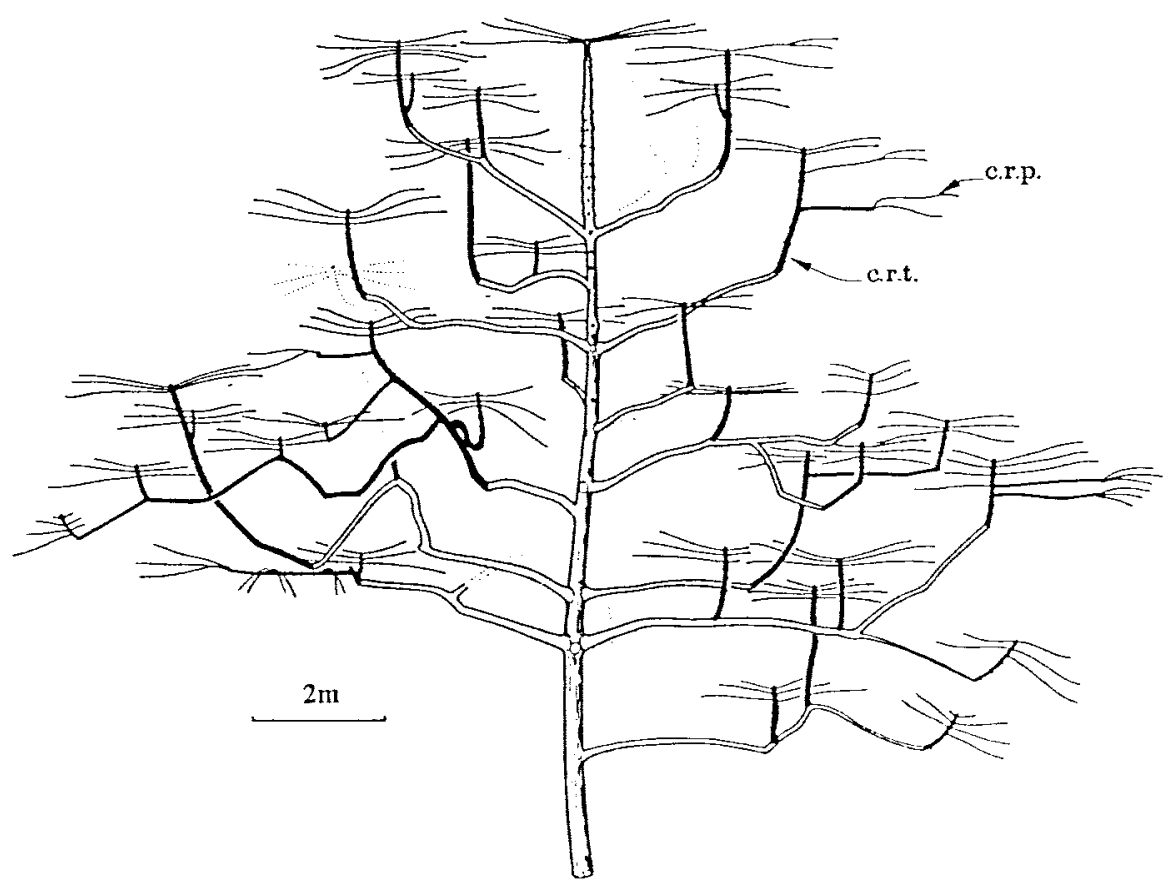

Fig. 1. Crown of a senescent tree of $V$. surinamensis. As in the branches of the young tree, the last branches developed by the trunk do not bear any reiterated complex (in bold black). c.r.p.: partial reiterated complex; c.r.t.: total reiterated complex; the leaves are not represented.

ganism develops the same architecture as that seen during the juvenile period, but following an inverted sequence of events.

\section{Invasion by flowering}

The ability to flower is used by several authors as a criterion to define the transition between the juvenile and the adult condition. Recent observations (Barthelemy, 1988) have shown that the location of flowers and inflorescences within the architecture of a plant may move progressively during its development. This invasion by flowering will be illustrated by two examples.
Symphonia globulifera L. f. (Clusiaceae) is a tropical tree whose architecture conforms to Massart's model (Fig. 2): a monopodial, orthotropic trunk bearing tiers of plagiotropic branches. Flowers are supported by order 5 axes, which are short shoots. During ontogenesis, the number of growth units between the point of insertion of a branch and its first flowering short shoot decreases from one tier to the following one. In other words, as the tree grows older, its new branches are able to flower more and more precociously.

Another example is given by a pioneer tree native to tropical South America: Isertia coccinea Vahl. (Rubiaceae). This tree conforms to Scarrone's model (Fig. 3a). The orthotropic, monopodial trunk 

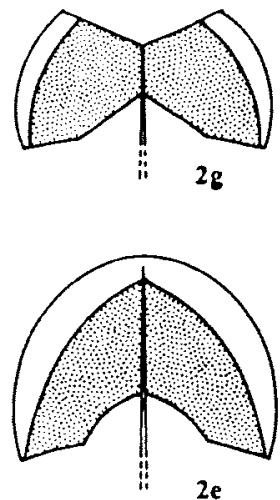

$2 \mathbf{e}$

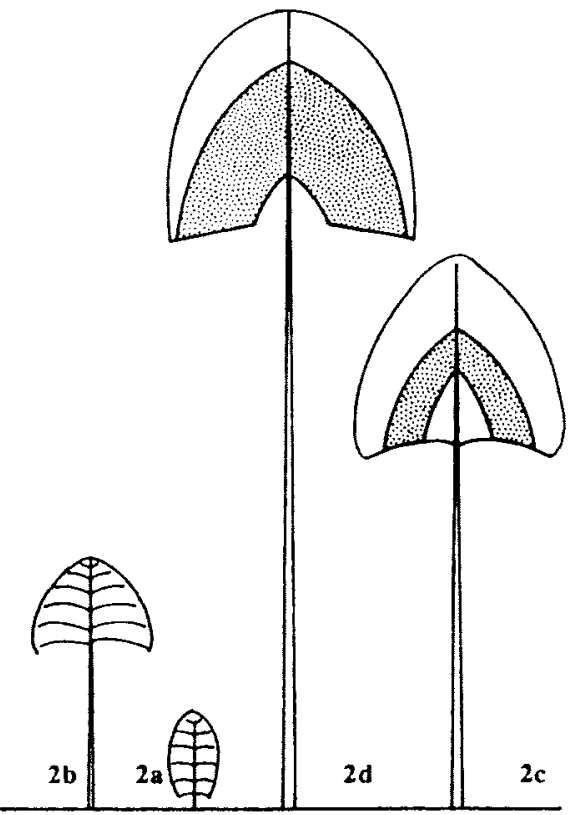

Fig. 2. Diagrammatic representation of the repartition of the inflorescences (stippled design) during the ontogenesis $(2 a-2 g)$ of $S$. globulifera. The growth of the young tree $(2 a, 2 b)$, is entirely vegetative and conforms to Massart's architectural model: the monopodial trunk is orthotropic and bears tiers of plagiotropic branches. After a few years (2c), the tree expresses its architectural unit and presents 5 categories of axes. Flowering occurs at this stage and flow-

ers are supported by order 5 axes which are short shoots. The first flowers occur in the middle of the lowest branches, but the number of growth units, between the point of insertion of a branch and its first flowering short shoot, decreases rapidly from one tier to the following one. Then, as the tree grows older $(2 \mathrm{~d}-2 \mathrm{~g}$ ), the fiowering area of the crown tends to become more and more important in comparison with the peripheral vegetative one. At last, the apex of the trunk dies (2g), and the whole crown flowers profusely. (From Barthelemy, 1988.) supports tiers of orthotropic branches which grow sympodially by virtue of terminal flowering. If we compare the length of branches at first flowering (Fig. 3b), we observe that the number of nodes below terminal inflorescences decreases according to the level of the branch on the trunk: the higher the branch, the smaller is the number of nodes. Then, as the tree grows older, it develops branches able to flower more and more precociously and after the formation of a decreasing number of nodes.

These two examples show that, during tree growth, flowering is progressively extended to all the vegetative structures, according to an acropetal flowering gradient, that underlie tree ageing.

\section{The proleptic reiterative process}

The occurrence of proleptic reiterated complexes in the crown of an old tree has been described by Oldeman (1972). It varies following various modalities in time and space, according to species, but recent investigations reveal the existence of a continuum between all these modalities. This will be demonstrated by 3 cases.

In Humiriastrum subcrenatum (Humiriaceae, French Guiana), reiterated complexes grow out on the upper side of the whole length of the limbs, when they are still growing. Such small 'individuals' develop in the crown and fill up the available volume. 

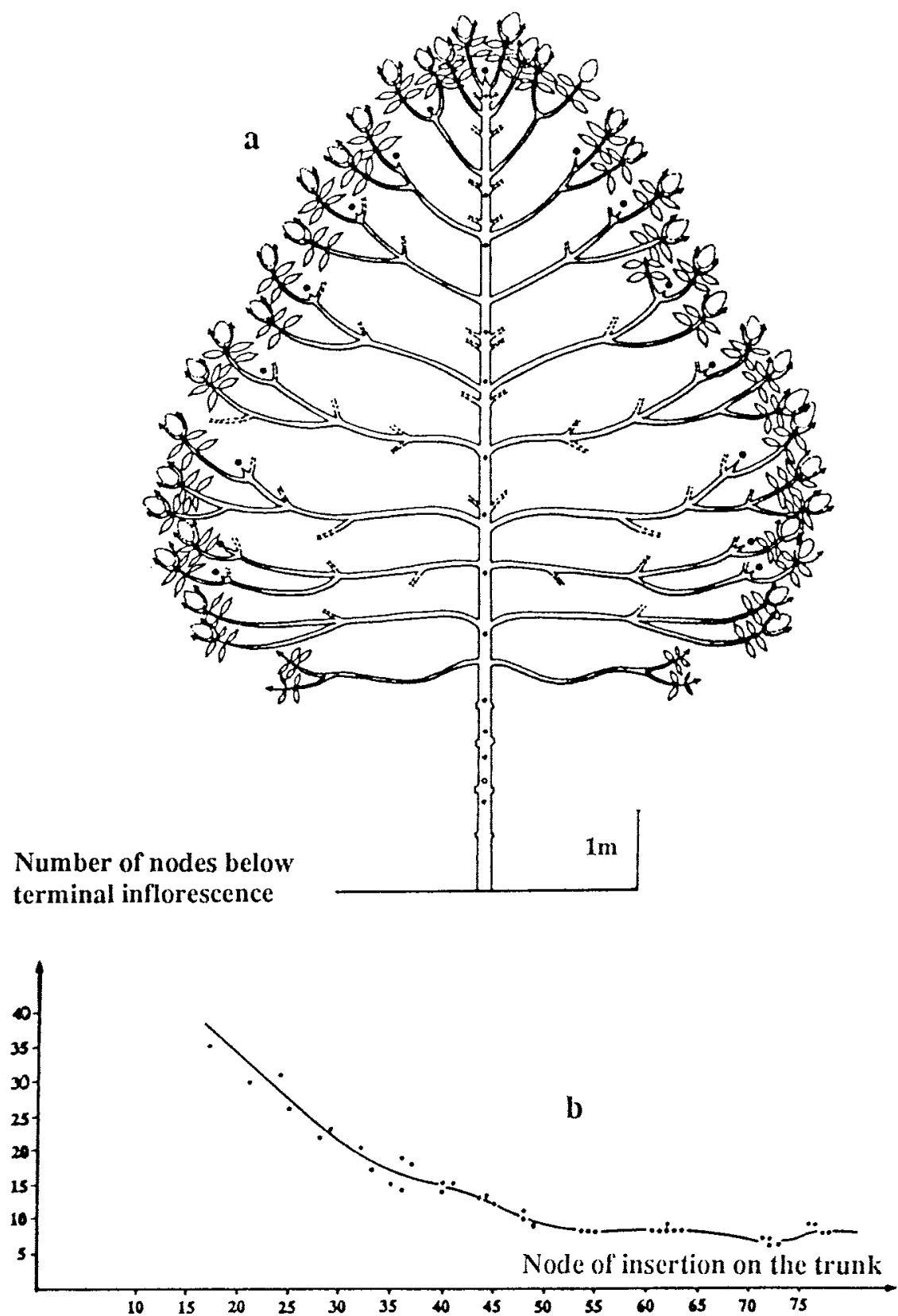

Fig. 3. Invasion by flowering in 1 . coccinea. a. Diagrammatic representation of the architecture which conforms to Scarrone's architectural model: all the axes of the tree grow sympodiaily by virtue of terminal flowering. $b$. Evolution of the number of nodes developed by the branches as a function of their location, represented by their node of insertion on the trunk. (From Barthelemy, 1988.) 
In Qualea rosea Aubl. (Vochysiaceae, French Guiana) the proleptic reiterated complexes occur only at the base of the limbs, near the trunk, when the crown has completed its development and is going to die. The simultaneous and probably coordinated development of the reiterated complexes leads to the building up of a new homogeneous crown which replaces the former one.

In Eperua falcata Aubl. (Caesalpiniaceae, French Guiana), the reiterated complexes, also appear at the base of the main branches and when the crown begins to lose its limbs, but their development is very delayed in space and time: the first complexes occur at the top of the crown, the following ones half-way on the trunk, and the last ones, some years before the tree dies, develop near the base of the bole.

Each of these species develops numerous proleptic reiterated complexes when ageing, but it is clear that crown architecture of the old tree evolves in different directions according io complex location and the mument of their appearance: it can lead to a reinforcement of the crown, to a lowering of the crown or to its complete replacement.

\section{Conclusion}

The reversion to a juvenile-like architecture, the invasion of the vegetative structures by flowering and the development of proleptic reiterated complexes are mor- phogenetic events which occur simultaneously and progressively, according to a sequence that is specific to each species. They lead us to distinguish numerous growth stages which punctuate tree ageing. In return, the knowledge of these stages enables us to determine with very high precision the true physiological states reached by an old tree, and these events can be used as markers of tree ageing and senescence.

\section{Acknowledgments}

This research has been financially supported by the CNRS (ATP 'Physiologie de la croissance et du développement des végétaux ligneux').

\section{References}

Barthelemy D. (1988) Architecture et sexualité chez quelques plantes tropicales: le concept de floraison automatique. Ph.D. Thesis, Université Montpellier II, France

Edelin C. (1977) Images de l'architecture des conifères. Ph.D. Thesis, Université Montpellier II, France

Halle F., Oldeman R.A.A. \& Tomlinson P.B. (1978) In: Tropicai Trees and Forests. SpringerVerlag, Berlin, pp. 441

Oldeman R.A.A. (1972) L'architecture de la forêt guyanaise. Ph.D. Thesis, Université Montpellier II, France

Schaffalitzky de Muckadell M. (1959) Investigations on ageing of apical meristems in woody plants and its importance in sylviculture. Forstl. Forsoegsvaes. Dan. 25, 310-455 